\title{
Le déracinement des populations en Casamance
}

Un défi pour l'État de droit

The Uprooting of the Population in Casamance. A Challenge to the Rule of Law

El desenraizamiento de las poblaciones de Casamance. Un desafío para el Estado

de derecho

\section{Nelly Robin}

\section{(2) OpenEdition}

\section{Journals}

Édition électronique

URL : https://journals.openedition.org/remi/2723

DOI : $10.4000 /$ remi.2723

ISSN : $1777-5418$

Éditeur

Université de Poitiers

\section{Édition imprimée}

Date de publication : 1 mars 2006

Pagination : 153-181

ISBN : 2-911627-41-5

ISSN : 0765-0752

Référence électronique

Nelly Robin, «Le déracinement des populations en Casamance », Revue européenne des migrations internationales [En ligne], vol. $22-n^{\circ} 1$ | 2006, mis en ligne le 01 avril 2009, consulté le 14 avril 2022.

URL : http://journals.openedition.org/remi/2723 ; DOI : https://doi.org/10.4000/remi.2723

Ce document a été généré automatiquement le 14 avril 2022.

(c) Université de Poitiers 


\title{
Le déracinement des populations en Casamance
}

\author{
Un défi pour l'État de droit \\ The Uprooting of the Population in Casamance. A Challenge to the Rule of Law \\ El desenraizamiento de las poblaciones de Casamance. Un desafío para el Estado \\ de derecho
}

\section{Nelly Robin}
« Le point d'équilibre est la parfaite égalité des droits entre les individus »
Élisée Reclus

1 Guerres civiles ou conflits internationaux sont très souvent à l'origine d'intenses mouvements de migration, volontaires ou forcés. Aujourd'hui, on estime à 19,2 millions le nombre de réfugiés et personnes relevant $\mathrm{du}_{\mathrm{HCR}}{ }^{1}$ et à 30 millions le nombre de personnes déplacées dans leur propre pays. L'ampleur et parfois la soudaineté de ces déplacements de populations peuvent menacer la stabilité des États.

2 Au sud du Sénégal, la Casamance, où depuis plus de vingt ans, un conflit oppose le gouvernement aux séparatistes du Mouvement des Forces Démocratiques de Casamance (MFDC), n'échappe pas à la règle. L'un des plus longs de l'Afrique subsaharienne, ce conflit a fait des centaines de morts, des milliers de blessés et des dizaines de milliers de personnes déplacées ou réfugiées. Les exodes ou les évacuations de populations, dus aux violents affrontements qui ont opposé l'armée sénégalaise au MFDC et à la propagation du banditisme inscrivent le « problème casamançais » dans la logique des territoires où l'État de droit est menacé.

3 En 2001, une première recherche, menée dans la région de Ziguinchor (Ndiaye et Robin, 2001), l'une des deux régions administratives de Casamance $^{2}$ et la plus affectée par le conflit, démontrait que les mouvements des déplacés ou réfugiés étaient une réalité à ne pas sous-estimer; ils représentaient alors $13 \%$ des habitants de Ziguinchor ${ }^{3}$. En outre, au cours des années 2001 et 2002, on assiste à une propagation du banditisme sans que l'on puisse déterminer l'origine réelle des hommes qui sèment la terreur dans 
les villages et sur les routes de Casamance. S'agit-il d'indépendantistes à la recherche de nourriture et de ressources financières ? Ou de bandes armées, formées de «bandits de grand chemin ", qui profitent de la confusion régnant dans la région pour voler, violenter ou même assassiner des villageois, déjà profondément éprouvés par plus de 20 ans de conflit?

Dans ce contexte, il est important de rappeler que dans "une société démocratique, le système judiciaire a la mission essentielle de garantir le fonctionnement de l'État de droit et de veiller au respect des droits et libertés consacrés par la Constitution $»^{4}$. En conséquence, pouvoir observer la possibilité qui est donnée à toute personne vivant en Casamance de disposer d'un « recours effectif devant les juridictions nationales compétentes contre les actes violant les droits fondamentaux qui lui sont reconnus par la constitution ou par la loi $»^{5}$ devient essentielle. Cela permet de mieux apprécier le statut incertain des territoires casamançais et les tendances centrifuges qui y sont à l'œuvre.

Ainsi, l'accès aux statistiques pénales, dont nous bénéficions dans le cadre du partenariat développé avec le ministère de la justice du Sénégal, revêt un intérêt incontestable. Elles sont élaborées à partir des informations notifiées dans les registres des plaintes et des procès-verbaux (RP) pour chaque affaire pénale. Les éléments recueillis sont les suivants : date d'enregistrement de l'affaire au parquet, rédacteur et lieu de rédaction des plaintes ou des procès-verbaux, identité, âge, sexe et nationalité de la victime, identité et filiation de la personne mise en cause (nom, prénom), date et lieu de naissance, âge, sexe, profession, domicile et nationalité de la personne mise en cause, infraction(s) commise(s), décision ou non de poursuite et mode de règlement de l'affaire, situation pénale de la personne poursuivie. Les statistiques pénales apportent donc des informations sur le lieu de commission de l'infraction, sur les victimes, sur la population mise en cause dans les procédures correctionnelles et sur les décisions prises par les chefs de parquet en termes de poursuite. Ainsi, elles permettent, non seulement d'analyser la délinquance, mais aussi de déterminer les modes de saisine (directe par les individus eux-mêmes ou indirecte par les autorités de police, de gendarmerie, des douanes, etc.) et d'apprécier la politique pénale.

D'un côté, le mode de saisine des autorités judiciaires, ici le parquet, révèle le sentiment du citoyen : sa demande de justice et la confiance accordée aux autorités intervenant aux différents stades de la procédure pénale. De l'autre côté, la décision de poursuivre ou non constitue le premier temps de la procédure pénale. Elle apporte un élément d'appréciation du degré de répression du parquet, évalué sur la base du nombre d'affaires classées sans suite pour inopportunité des poursuites. Si l'on excepte les classements sans suite, destinés à écarter les affaires incertaines ou douteuses, «[...] classer ou poursuivre, [...] est probablement l'option la plus importante dans le fonctionnement de la justice pénale. Le choix du mode de règlement, deuxième temps de la procédure, reflète les grands axes de la réponse pénale appliquée par les chefs de parquets ».

7 Dès lors, l'analyse des statistiques pénales éclaire sur le fonctionnement de la Justice et renseigne sur la qualité des relations établies avec le justiciable. Ces questions de société sont aujourd'hui au cœur des préoccupations des populations casamançaises et des autorités du Sénégal.

8 Toutefois, l'utilisation de données administratives peut être source de difficultés; l'antinomie entre les impératifs de l'état, préoccupé d'affirmer et d'affermir sa souveraineté nationale, et les impératifs de la recherche, soucieuse d'indépendance et 
du respect de l'éthique scientifique constitue un risque sous-jacent. Mais, ces tensions potentielles peuvent être levées par le respect de deux principes essentiels formulés par Geffray (1998 : 174) :

1. le "premier principe" est dans l'affirmation sans équivoque de notre "claire identité de chercheurs » qui n'autorise aucune ambiguité sur les fondements de notre démarche ;

2. le « second principe » implique « l'existence au plus haut niveau de l'administration de l'État d'une relation de confiance, avec un ou plusieurs hauts fonctionnaires assumant des responsabilités dans une ou des institutions. " Pour parvenir à croiser, dans un contexte de conflit armé, des données sur les migrations forcées avec des données aussi sensibles que celles de la justice, "quelqu'un doit assumer la responsabilité publique et administrative de notre recherche, tout en nous donnant la possibilité formelle de travailler. »

9 Ces principes ont prévalu pour la recherche présentée ici. L'accord formel signé avec le Ministère de la Justice nous donne accès à une documentation et à une information administratives, la confiance mutuelle qui s'est établie avec plusieurs représentants de la haute fonction publique préserve notre autonomie et notre indépendance de chercheur.

Le croisement entre ces données produites par les institutions étatiques et des données provenant d'une part, d'autres sources statistiques - société civile ou organisations internationales (UNICEF, Handicap International) -, d'autre part, d'entretiens et d'enquêtes réalisées soit dans les communautés villageoises dont sont originaires les personnes déplacées ou les réfugiés, soit dans les quartiers d'accueil de Ziguinchor, permet de mettre en corrélation les mouvements récents de population et les crimes et délits portés à la connaissance des tribunaux.

11 Sur cette base, il s'agit de réinterpréter les migrations de réfugiés ou de personnes déplacées pour comprendre les processus qui les ont générées, appréhender leur évolution et apprécier leurs implications sociales et politiques sur la situation actuelle de la Casamance.

Dans une première étape, nous essayons de retracer l'histoire du conflit afin d'identifier les événements majeurs qui ont provoqué des déplacements forcés de population. Dans un second temps, nous nous intéressons plus précisément aux migrations récentes, liées aux " opérations de ratissage de l'armée » ou aux exactions et aux pillages perpétrés par les rebelles dans les villages. Un parallèle est ensuite établi entre les rapports que les populations de Casamance ont entretenu avec l'administration coloniale et les relations qu'elles ont avec les représentants de l'État du Sénégal depuis le début du conflit. Cette mise en perspective de deux temps de l'histoire permet de mieux comprendre les fondements de la défiance des populations à l'égard des autorités administratives ou militaires et l'importance de la question foncière dans une perspective de paix. Cela nous conduit à nous interroger sur la manière dont l'État répond à la revendication indépendantiste du MFDC et la perception qu'en ont les populations casamançaises. Enfin, nous tentons de comprendre ce qui, dans ce contexte, motive les mouvements de retour, observés récemment dans quelques villages.

\section{Vingt ans de conflit, cinq périodes clés}

13 Après plus de vingt ans de conflit, ponctués de cessez-le-feu successifs et de scissions au sein du MFDC, l'insécurité affecte de nouvelles zones et la confusion s'installe entre 
rébellion et banditisme. En mars 2001, l'abbé Diamacoune, secrétaire général du MFDC, dénonce lui-même cette dérive : "aujourd'hui plus que jamais je condamne énergiquement [...] ces criminels prétendant se réclamer de moi et refusant toujours de m'obéir. Ils se sont donc séparés de moi. Et je dégage toute responsabilité dans ces crimes abominables qu'ils commettent partout. $»^{6}$

\section{Ferments d'une rébellion armée}

14 Au cours des années 70, les émissions de radio, animées par l'abbé Diamacoune Senghor sur l'antenne régionale de la ORTS ${ }^{7}$, retracent l'histoire de la Casamance et deviennent peu à peu un forum où les populations expriment leurs frustrations: spoliations de terres, en milieu urbain comme en milieu rural, imposition d'une loi sur le domaine national et d'un code forestier ne tenant pas compte des us et coutumes de la région, mépris culturel dans lequel les populations casamançaises sont tenues par les « gens du nord $»^{8}$. Dès lors, les propos du religieux glissent vers la dénonciation du comportement des "étrangers", fonctionnaires ou commerçants venus d'autres régions du Sénégal, vis-à-vis des autochtones; le sentiment d'une identité casamançaise ou d'un particularisme joola se renforce dans l'esprit des auditeurs. L'homme d'église construit ainsi un discours indépendantiste ${ }^{9}$. Pour relayer cette revendication, en 1981/1982, le Mouvement des Forces Démocratiques de la Casamance (MFDC) est fondé ; il porte le nom du parti politique créé par Émile Badiane et Ibou Diallo, en 1947/1948, dans le but de permettre à des élus casamançais de siéger à l'assemblée du Sénégal ${ }^{10}$.

L'appropriation des terres de la région par des autorités locales "étrangères ", représentant le pouvoir central, au détriment des populations de Casamance, et le mépris dont les populations joolas font l'objet, constituent donc les ferments de la revendication indépendantiste, portée par l'abbé Diamagoune.

Ainsi, le 26 décembre 1982, à Ziguinchor, alors capitale régionale de la Casamance ${ }^{11}$, un millier de personnes tentent d'enlever le drapeau sénégalais qui flottait au-dessus de la gouvernance ${ }^{12}$. Des tracts du MFDC appellent à l'indépendance; manifestation qui peut être considérée comme l'acte fondateur de la revendication indépendantiste.

Un an après, presque jour pour jour, le 18 décembre 1983, une nouvelle manifestation indépendantiste, à Ziguinchor, se solde par 25 morts et plus de 260 arrestations, dont celle de l'Abbé Diamacoune, chef historique du MFDC, libéré cinq ans plus tard, dans le cadre d'une loi d'amnistie qui absout toutes les infractions criminelles ou correctionnelles commises entre le $1^{\mathrm{er}}$ janvier 1982 et le 31 juillet 1987 au Sénégal ou à l'étranger, en rapport avec les évènements de Casamance.

\section{Cessez-le-feu successifs et scissions au sein du MFDC}

En mai 1991, les accords de Cacheu (Guinée Bissau) débouchent sur un premier cessezle-feu entre le gouvernement et les indépendantistes et sur le vote d'une nouvelle loi d'amnistie prévoyant la libération de tous les rebelles détenus.

Mais, ces accords provoquent une radicalisation au sein du mouvement qui se scinde en deux tendances : «le Front nord », représenté par Sidy Badji13, accepte la négociation, le « Front sud », représenté par l'abbé Diamagoune, revendique l'indépendance. 
20 S'ouvre alors une période de violences où alternent attaques du MFDC, plus précisément du «Front sud», et répressions des forces de l'ordre. Au cours de ces affrontements les deux parties procèdent à des représailles contre les populations civiles. Selon une dépêche de l'AFP, «près d'un millier de personnes ont trouvé la mort en Casamance entre juillet 1992 et juillet 1993 ».

21 En décembre 1993, un troisième accord de cessez-le-feu provoque une nouvelle scission au sein du «Front sud» du MFDC. La reprise des combats par l'aile radicale du mouvement ${ }^{14}$ autour des villages de Niaguis, Boffa ou Kaguitte, notamment, et le long de la frontière bissau-guinéenne, à proximité des villages de Ponta Rosa et d'Ingor en particulier, entraîne le repli des populations civiles sur la ville de Ziguinchor et dans des camps placés sous l'autorité du HCR à l'intérieur du territoire bissau-guinéen. (Par exemple, en 1994, 7189 familles sont répertoriées dans les seuls camps de Sao Domingos, Lampada et Suzana).

\section{Extension d'ouest en est des zones de combat}

l'opposent au «Front sud » du MFDC poussent les populations à fuir leurs villages pour trouver asile dans quelques zones dites sécurisées par l'armée et surtout dans la ville de Ziguinchor ou en Guinée-Bissau. Ainsi, en 1996, un responsable de la sécurité en Casamance estimait à plus de 22000 le nombre de personnes réfugiées en GuinéeBissau.

En 1997, après une accalmie de dix-huit mois, les violences reprennent et les mines anti-personnelles font leur apparition. Au cours de cette seule année, Handicap international $^{15}$ identifie 159 victimes de mines, soit environ $40 \%$ des victimes répertoriées entre 1988 et 1999.

Les zones de "refuge " ne sont plus épargnées : des incidents éclatent aux portes de Ziguinchor et l'armée mène une offensive le long de la frontière bissau-guinéenne. Les populations quittent alors les périphéries de Ziguinchor. En juin 1997, le HCR dénombre 17000 réfugiés casamançais répartis entre la Guinée-Bissau et la Gambie.

27 Cependant, la rébellion militaire qui ébranle la Guinée-Bissau en $1998^{16}$ a deux incidences majeures sur la gestion du conflit casamançais :

1. la constitution d'un nouveau gouvernement bissau guinéen qui applique une politique différente à l'égard notamment des chefs rebelles du «Front sud » dont la Guinée-Bissau a été longtemps accusée d'abriter les bases arrière. En janvier 2001, le colonel Tag Na Waï, commandant de la zone nord de Guinée-Bissau, déclare à l'AFP que «l'armée bissau guinéenne est décidée à "nettoyer" les bases arrière des rebelles casamançais sur son territoire (et qu'elle) est prête à lancer un assaut final contre l'état-major de Salif Sadio. "Dans une lettre adressée aux "Secrétaires généraux des différents partis politiques de Guinée-Bissau », Salif Sadio, lui-même, dénonce les opérations organisées par l'armée guinéenne contre le MFDC: «des éléments 
basés à Bissau même, habillés, armés et soutenus en hommes et en logistique par l'armée de GuinéeBissau, sont venus de Bissau (la capitale) et environs, attaquer certaines bases du Maquis du MFDC. $»^{17}$

2. l'expulsion de réfugiés casamançais, soupçonnés d'être, selon les autorités bissauguinéennes, des parents ou alliés des combattants du MFDC ${ }^{18}$.

$\mathrm{Au}$ cours de ces vingt ans de conflit, dans toutes ces zones stratégiques, la violence des affrontements a donc entraîné un exode de 30000 à 50000 personnes, et un abandon des villages ( $12 \%$ dans la région de Ziguinchor); les arrondissements de Nyassia et de Niaguis, situés au sud, entre le fleuve Casamance et la frontière bissau-guinéenne, ayant été les plus affectés.

Carte 1 : Répartition des victimes de mines par localité en Casamance de 1988 à 2000

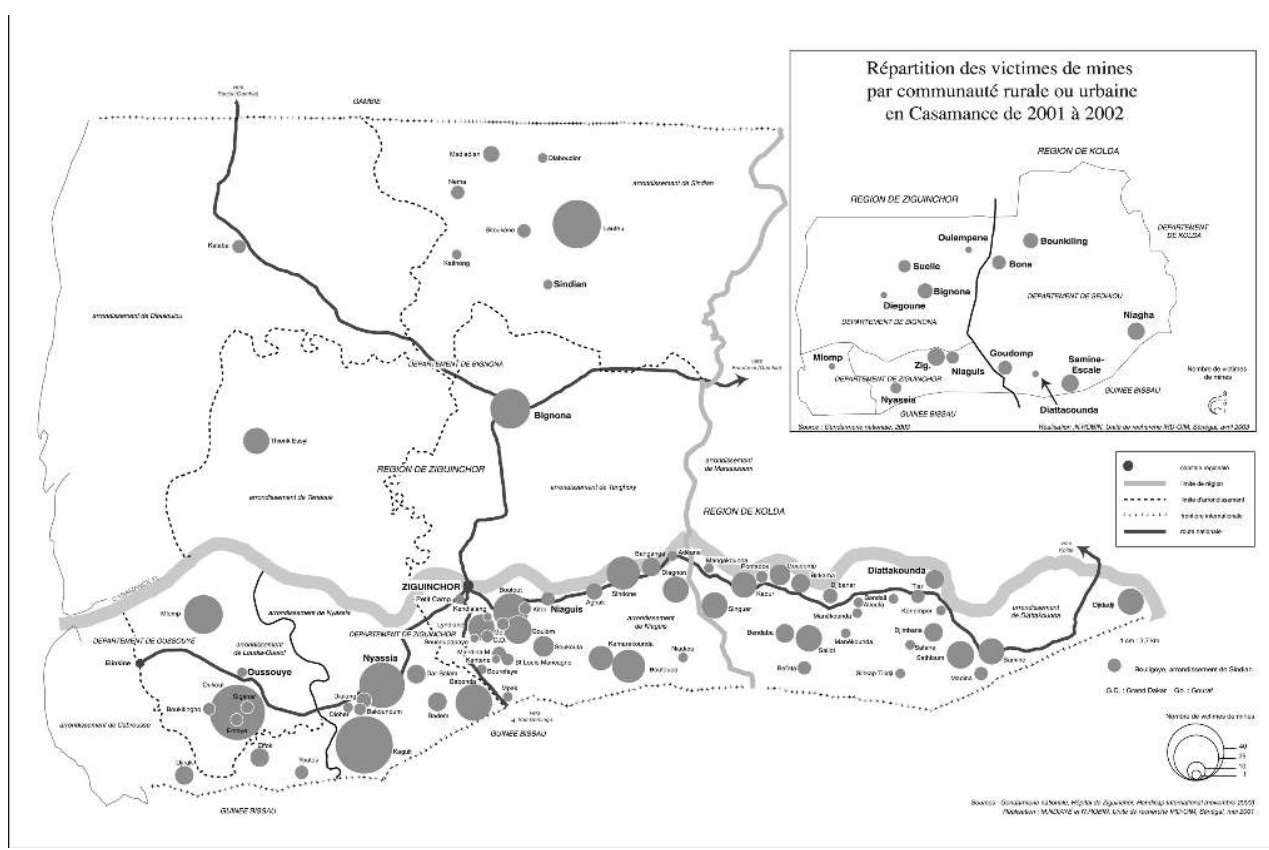

La carte 1 montre l'importance des accidents par mines au sud-ouest et au sud-est de Ziguinchor et leur extension dans les départements de Bignona et de Sedhiou, depuis l'année 2000. Les terres des arrondissements de Nyassia, de Niaguis et de Diattacounde sont aujourd'hui, totalement ou pour partie, « interdites » à la culture en raison des mines. Le déminage constitue donc l'une des conditions préalables au retour des populations dans leur village d'origine. Mais son organisation sera d'autant plus difficile que si les militaires peuvent établir une carte des zones qu'ils ont minées, par contre, les rebelles sont dans l'impossibilité de faire de même. En outre, cette partie de la Casamance est marécageuse et, sous l'effet des pluies, les glissements de terrain ont entraîné une partie des mines vers d'autres zones que celles qui ont été répertoriées. Par ailleurs, on sait que toute opération de déminage est délicate et longue. Des experts du PNUD estimaient en 2001 que dix ans seraient nécessaires pour déminer la Casamance! Techniquement, le déminage commence à une extrémité de la zone "polluée» et avance progressivement vers l'autre extrémité; ainsi, plusieurs années pourraient séparer le déminage de l'ouest du département de Oussouye du déminage de l'est du département de Sedhiou. Il y a là un enjeu majeur pour les populations, déplacées ou réfugiées, aujourd'hui privées de leurs moyens d'existence; pour elles, quelle que soit leur zone d'origine, le règlement du conflit est avant tout synonyme de retour à la terre, génératrice de revenus. 


\section{Populations déracinées, entre conflit et paix}

En 2001 et en 2002, face à un regain des actes de violence, selon les zones, et les enjeux locaux (avoués ou non ${ }^{19}$ ), l'État réagit différemment, mais les effets sont comparables à ceux qui sont observés par le passé: mouvements forcés de populations et communautés villageoises déracinées.

31 Au sein de la région de Ziguinchor, dans la zone dite du «Front nord», considérée comme pacifiée depuis 1993, face à une recrudescence des braquages et des pillages, notamment sur les axes reliant Ziguinchor à la Gambie, l'armée sénégalaise a organisé deux opérations de ratissage. Ces interventions, en $2001^{20}$ et $2002^{21}$, ont provoqué des déplacements de populations d'une ampleur sans précédent dans cette partie de la Casamance et la création de nouveaux camps de réfugiés en Gambie.

\section{Regain de violences et mouvements d'exode}

Au cours du mois de juillet 2002, 324 familles soit plus de 3600 personnes ont fui leurs villages, dans les arrondissements de Diouloulou et de Sindian (département de Bignona) ${ }^{22}$. En août 2002, 11000 réfugiés casamançais sont recensés en Gambie par la Croix Rouge et le $\mathrm{HCR}^{23}$; parmi eux, 4000 réfugiés sont accueillis par les populations locales, principalement dans les régions gambiennes de Lower River et de Western Division, situées le long de la frontière avec le Sénégal, les autres réfugiés étant répartis dans différents camps.

Depuis, la plupart des réfugiés, confrontés à des conditions d'existence extrêmement précaires, ont préféré prendre le risque de repartir dans leur village ou ont rejoint la ville de Ziguinchor. Cette nouvelle mobilité forcée a accru encore la pression démographique sur la capitale régionale et la paupérisation des populations, un grand nombre de déplacés en ville n'ayant plus accès à leurs terres tout en n'ayant pas trouvé de travail.

Au même moment, dans la région de Kolda, exactions et pillages des rebelles contre les villageois et les fonctionnaires (instituteurs ou infirmiers notamment) se multiplient et s'étendent à de nouveaux secteurs. Les interventions ponctuelles et circonscrites de l'armée ne parviennent pas à sécuriser la zone et à rassurer les populations qui se trouvent, là aussi, contraintes de fuir leur village et de chercher refuge à Kolda, la capitale régionale.

35 Ainsi, en mars 2001, plus de $18000^{24}$ personnes déplacées y sont dénombrées et elles sont encore plus de 4000 en novembre $2002^{25}$. Pourtant, aucun périmètre d'accueil n'a été aménagé par l'État ou les organisations internationales. Seul un comité est créé, à l'initiative du gouverneur de la région, après l'attaque des villages de la communauté rurale de Médina El Hadj au cours de la nuit du 25 au 26 février 2002, pour distribuer une aide alimentaire d'urgence aux populations rassemblées dans une sorte de terrain vague, puis plus rien.

36 En fait, ces nouveaux mouvements de population placent l'État face à un dilemme : si dans la région de Kolda, il planifie et aménage avec ou sans l'aide de la communauté internationale, des espaces pour accueillir les populations fugitives, il convient de la gravité du phénomène, et il reconnaît l'extension du conflit à des zones jusqu'alors 
épargnées par les violences. À l'inverse, s'il ne porte pas secours aux populations, il prend le risque d'être accusé de violation de la Déclaration universelle des droits de l'homme, laquelle prévoit que « tout individu a droit à la vie, à la liberté et à la sûreté de sa personne. » (Article 3).

\section{Une réponse de l'État qui fait fi de l'histoire}

37 Ainsi, pour mieux comprendre le jeu de relations complexes qui s'est établi entre l'État et les populations de Casamance, avec les « opérations de ratissage » dans le front nord et les opérations de « sécurisation » le long de la frontière bissau-guinéenne, il convient de les lire à la lumière de l'histoire.

Si, en juin 2001, l'« opération de ratissage » déclenchée par l'armée sénégalaise dans le front nord contraint les populations de l'arrondissement de Sindian à fuir et à se réfugier en Gambie, à la première accalmie, elles reviennent reconstruire leur village brûlé ou dévasté par les combats. Un an plus tard, une nouvelle opération de ratissage a le même effet, la fuite des populations en Gambie, et les mêmes conséquences, frustrations et défiance à l'égard de l'autorité centrale. Or cette alternance d'accalmies et de regains de tensions entre Pouvoir Central et populations casamançaises est, si l'on peut dire, une très vieille "tradition "; ainsi, en 1887, après l'occupation de Suele ${ }^{26}$, le capitaine Lauqué ne se faisait guère d'illusion en commentant les soumissions des populations, obtenues par l'administration coloniale : «au point de vue pacification, il est très probable que, comme du reste l'année dernière, la crainte du châtiment immédiat étant dissipé [...], les querelles et les brigandages vont recommencer pendant le prochain hivernage, les populations ne se pliant que difficilement à l'autorité, même lorsque celle-ci est appuyée par des forces militaires importantes. »

Ce rappel historique montre déjà que la question des réfugiés et des personnes déplacées relève souvent d'une longue expérience des rapports entre État et populations locales. Comme le fait observer M.A. Pérouse de Montclos à partir du cas des réfugiés somaliens au Kenya, "les migrations forcées sont anciennes, recoupant parfois de vielles routes d'exode ou de conquête. Ce sont les récupérations à des fins politiques, la redéfinition du réfugié par le droit humanitaire et l'intervention de la communauté internationale qui donnent au problème une autre ampleur et par là même un brevet de modernité. » (1998: 155-172)

Cette hypothèse est ici renforcée par la comparaison possible entre les rapports de l'administration coloniale, faisant état des missions de pacification en Casamance, notamment dans le Foñi ${ }^{27}$, et les dépêches de l'AFP relatant les "opérations de ratissage " menées par l'armée sénégalaise dans le département de Bignona en 2001 et 2002 : on peut en effet y relever des analogies entre les mouvements de populations du début du $\mathrm{xx}^{\mathrm{e}}$ siècle et les migrations forcées du début $\mathrm{du} \mathrm{xxI}^{\mathrm{e}}$ siècle.

41 En 1916, l'administrateur Brunot préparant un "Plan de pacification de la Casamance » s'étonnait que cette région, occupée depuis longtemps, ne fût pas encore entièrement soumise. Il expliquait notamment cela par le fait que ce pays est un «refuge inviolable des habitants qui leur permet de laisser passer les colonnes sans qu'il résulte pour eux d'autres sanctions que l'incendie des toits de paille des cases abandonnées et préalablement vidées de leur contenu $»^{28}$. Brunot estimait aussi que les « rebelles» du Foñi détenaient 10000 fusils et que le désarmement devait être assuré par une troupe de 200 hommes venus de Dakar. Et il précisait que « le réarmement toujours possible serait empêché par une surveillance active 
des frontières. ». L'historien Roche,commentant ce rapport remarquait à juste titre que « la Casamance était un long couloir entre deux colonies étrangères où à l'occasion se réfugiaient temporairement les rebelles. »(1985: 288)

Or, il est frappant de constater qu'environ, un siècle plus tard, le 26 mai 2001, une dépêche de l'AFP annonçait, quasiment dans les mêmes termes, que l'armée sénégalaise avait entrepris « une vaste opération de ratissage qui s'est traduite par des combats à l'arme lourde et a provoqué la fuite de populations civiles paniquées. Une femme originaire du village de Tanding (département de Bignona) a affirmé que son village avait été détruit par des soldats sénégalais qui ont incendié la plupart des maisons, à la recherche des rebelles. "Quelques jours plus $\operatorname{tard}^{29}$, une nouvelle dépêche disait avoir appris auprès du HCR que «la majorité des quelque 1400 réfugiés arrivés en début de semaine de Casamance en Gambie étaient rentrés chez eux, les combats entre l'armée sénégalaise et les rebelles indépendantistes ayant apparemment cessé. »La même dépêche précisait que «l'armée sénégalaise contrôle la localité frontalière de Séléti, qui avait été attaquée en début de semaine par la rébellion. »

43 Ces "opérations de ratissage " dans le front nord, renforcées par les "opérations de sécurisation » le long de la frontière bissau-guinéenne, ont participé au développement de la défiance des populations locales à l'égard des autorités administratives ou militaires.

Pour dire ce fossé qui sépare, bien souvent, aujourd'hui encore, les populations de Casamance de l'État Central, on pourrait emprunter à l'administrateur supérieur Guyon ses commentaires sur les méthodes adoptées par l'administration coloniale pour réprimer la résistance des Seleki et des Bayot, à la fin du XIX ${ }^{\mathrm{e}}$ siècle : "les colonnes de police (ne sont) pas très efficaces [...], impuissantes à imprimer dans l'esprit particulariste des indigènes, la notion de l'autorité permanente, l'idée d'une force qui tient presque tout le pays, à laquelle les fauteurs de désordre ne peuvent échapper et qui est en mesure de protéger les braves gens... »(Roche, 1985 : 287)L'administrateur poursuivait : la pacification des groupements réfractaires serait donc par là, un perpétuel recommencement ».

Ce rapprochement entre l'histoire contemporaine et l'histoire coloniale n'est donc pas un exercice de style. Il puise ses fondements dans la réalité quotidienne des populations de Casamance. Christian Roche (1985: 286) rappelle ainsi que "la résistance de Jinaboo ${ }^{30}$ » face à l'administration coloniale par laquelle il fût tué, "est un fait prestigieux pour les Jolaas. Ils ont aujourd'hui donné son nom au lycée de Ziguinchor. »

46 Ainsi, opposer à la résistance de la Casamance la violence des forces armées n'a jamais été le bon moyen de convaincre les populations de la légitimité de l'autorité centrale ou de la capacité de l'État à les protéger.

À l'inverse, lorsque le pouvoir colonial fut représenté par un administrateur privilégiant le dialogue à la violence et prenant l'initiative de remplacer les chefs étrangers au pays, (malinkés ou toucouleurs), par des chefs joolas, la population accepta leur autorité. Roche rapporte ainsi les faits suivants : «dans le Fooñi, les Joola de la région de Sinjian-Balandine se révoltèrent au mois de décembre 1915 contre des chefs de canton malinkés imposés par les résidents militaires de Biñona. [...]. De Copet, administrateur du cercle de Ziguinchor, congédia les chefs malinké et les remplaça par un Joola [...]. Peu à peu, les Joola de la région de Sinjan-Balandine acceptèrent son autorité, notamment pour la perception de l'impôt... »De même aujourd'hui, si les populations Joola reconnaissent l'autorité de l'État sénégalais et ne revendiquent plus l'indépendance de la Casamance, elles entendent toutefois s'administrer elles-mêmes. Les propos recueillis, en janvier 2003, auprès d'un habitant de Ziguinchor, impliqué dans le processus de paix, témoigne de 
cette détermination: "l'indépendance proprement dite de la Casamance n'est plus notre combat; mais si l'état sénégalais veut négocier la paix, il doit nous accorder l'autonomie de gestion de certains secteurs-clés de la vie politique et économique de la région. »

\section{La question foncière, une priorité pour le retour des personnes déplacées ou réfugiées} partie importante des rizières et des champs de culture par l'armée sénégalaise ou par le MFDC, ont accru la rareté et la valeur de la terre et, de fait, favorisé de nouvelles spéculations foncières. Le retour des populations déplacées ou réfugiées risque donc d'engendrer des relations conflictuelles entre communautés villageoises, donc de faire planer des incertitudes sur l'établissement d'une paix durable.

51 Les entretiens que nous avons menés en 2002 auprès des habitants des villages de Niaguis et de Fangot, au sud-est de Ziguinchor, nous ont permis de recueillir des témoignages qui illustrent ces risques.

52 Au début des années 1990, les habitants de Fangot, alternativement persécutés par les maquisards et attaqués par les militaires, ont dû abandonner leurs maisons et leurs terres; la plupart se sont réfugiés à Ziguinchor ou à Niaguis, le village le plus proche, sur l'axe routier Kolda-Ziguinchor. Dans le même temps, à la suite de différentes attaques menées par les maquisards, certains habitants de Niaguis ont préféré partir à Ziguinchor. Aussi, ont-ils libéré des rizières que les réfugiés de Fangot, contraints d'abandonner leurs terres, minées ou situées dans une zone à risque, ont pu exploiter avec le consentement de la communauté villageoise de Niaguis.

Or, le jour où la paix sera effective, les populations de Niaguis déplacées à Ziguinchor n'auront, a priori, aucune difficulté pour rejoindre leur village d'origine, non miné et sécurisé ; légitimement, elles souhaiteront alors exploiter leurs terres prêtées pendant leur absence aux populations de Fangot. Tout serait simple, si ces dernières pouvaient repartir aussi facilement dans leur propre village d'origine ; mais, Fangot est détruit et les voies d'accès aux rizières sont minées. Ainsi, peuvent naître des conflits fonciers entre les populations déplacées de Fangot, exploitant les rizières de Niaguis, et les populations déplacées de Niaguis de retour pour récupérer leurs terres. En outre, au cas 
où les populations déplacées de Fangot rétrocéderaient sans difficulté les terres à leur propriétaire, un autre problème se pose : les villageois de Fangot se retrouvent sans terre, plus exactement avec des terres inexploitables puisque minées. Une telle situation porte en elle-même les germes d'un nouvel exode vers Ziguinchor, en quête d'un travail ou d'une assistance auprès de familles déjà durablement appauvries par 30 ans de conflit!

Si dans un tel cas, on peut espérer que les conflits fonciers pourront être apaisés grâce à la bonne volonté de chacun, rien n'est moins sûr, dans d'autres situations plus complexes. En effet, le climat de guerre a favorisé l'appropriation arbitraire de terres par certains individus convaincus de bénéficier d'une totale impunité, grâce à leur appartenance familiale ou politique. À l'inverse, craignant des représailles, les villageois victimes n'osent pas dénoncer ces dépossessions arbitraires par des autorités locales ou certains membres de leur famille ce qui n'est pas sans rappeler les méthodes adoptées par le passé et qui ont été à l'origine de profondes frustrations, sur lesquelles s'est appuyée la revendication indépendantiste. Ainsi, la paix venue, les populations spoliées n'accepteront probablement pas d'être privées définitivement de leurs terres de culture et elles revendiqueront un retour à la situation antérieure. Si cette aspiration légitime n'est pas satisfaite, il est à craindre qu'un profond sentiment de révolte se développe. À l'inverse, ceux qui se sont approprié les terres et les ont valorisées durant le conflit, risquent ne pas vouloir les rétrocéder aux premiers propriétaires. Sur cette base, les antagonismes anciens entre autochtones et " étrangers ${ }^{33}$ " peuvent se réactiver. Il y a là risque de conflits entre villages ou, pis, entre groupes ethniques ce qui peut hypothéquer la réinstallation des populations déplacées dans leur village d'origine et le processus de paix.

Si pour montrer l'importance probable des litiges fonciers, nous avons eu recours à des exemples précis et localisés, ce problème concerne, néanmoins, l'ensemble des terroirs villageois, et plus encore ceux situés au sud de Ziguinchor, de l'Atlantique au département de Kolda.

Bien sûr, les risques sont d'une intensité variable selon les situations. Mais, dans tous les cas, l'accès aux zones de culture, minées ou "confisquées ", apparaît comme la condition sine qua non du retour des personnes déplacées et constitue, de fait, un vrai défi pour une paix durable, d'autant plus qu'une réelle méfiance subsiste face aux autorités locales qu'il s'agisse des cadres de l'administration, pour la plupart d'origine " étrangère ", ou qu'il s'agisse des militaires, qui recourent trop souvent à la répression et à la délation ${ }^{34}$.

Parallèlement, la manière dont la justice est interpellée par les populations du département de Sedhiou ${ }^{35}$, victimes d'actes de violence, perpétrés par des rebelles ou des bandes armées, traduit à la fois leur reconnaissance de l'autorité centrale et leur défiance à l'égard de l'autorité locale. Ce sentiment ambivalent exprime pleinement l'inquiétude des Casamançais face à un État qui, en réponse à l'insécurité, privilégie la violence des forces armées et laisse s'affaiblir l'État de droit en marginalisant, de fait, l'autorité judiciaire.

\section{Une justice marginalisée, un état de droit fragilisé}

Dans cette perspective, l'analyse des délits et crimes portés à la connaissance des tribunaux de la région de $K_{\text {olda }}{ }^{36}$, et plus particulièrement du département de 
Sédhiou ${ }^{37}$, confirme l'existence d'une « zone où l'État s'estompe ». Pas une semaine sans que les quotidiens nationaux ou les dépêches des agences de presse ne relatent un accident par mines antipersonnelles, une attaque de village ou un braquage de véhicules dans cette zone. Pourtant l'observation des informations enregistrées au registre des plaintes du parquet de Sedhiou semble indiquer que la délinquance n'augmente pas et n'a pas les caractéristiques d'une zone de conflit armé. Quel sens donner à ce paradoxe apparent?

\section{Diminution de l'activité des parquets de la région de Kolda}

Pour apporter des éléments de réponse à cette question, nous disposons de l'ensemble des données enregistrées dans les registres des plaintes des parquets de la région de Kolda (Kolda, Sedhiou et Vélingara) entre 1998 et 2001. Globalement, le nombre d'affaires traitées par les tribunaux de la région de Kolda diminue significativement au cours de cette période (baisse de près de $20 \%$ (3) $^{38}$. Toutefois, cette tendance générale masque des évolutions inégales selon les lieux, ce qui peut être le reflet de l'activité inégale des officiers de police judiciaires. Seule la ville de Kolda a enregistré une augmentation significative du nombre de personnes mises en cause. À l'inverse, ce nombre s'est stabilisé dans les secteurs de Bounkiling et de Samine-Escale.

Les statistiques pénales indiqueraient donc que la délinquance se serait développée essentiellement en zone urbaine. Par contre, l'accroissement des actes de violence qui affectent les axes routiers comme le milieu rural du département de Sedhiou et ont conduit les habitants des communautés rurales situées le long de la frontière bissauguinéenne, notamment celles de Diattacounda et de Samine Escale, à abandonner leurs villages, apparaît peu dans les statistiques pénales.

61 Ainsi, les dispositions visant à endiguer les violences et à protéger les personnes ne semblent pas appliquées de manière égale en milieu urbain et en milieu rural ; le sud du département de Sedhiou, pourtant profondément touché par les attaques menées contre les villageois, ne paraît pas bénéficier de la même attention que la ville de Kolda.

\section{Une délinquance constatée par les forces de l'ordre le long des axes routiers, dénoncée par les populations elles-mêmes en milieu rural}

62 Une observation plus détaillée, selon la nature des infractions et le mode de constatation des affaires pénales traitées par le parquet régional de Kolda et provenant du département de Sedhiou, permet d'étayer l'analyse.

63 La plupart des affaires provenant du département de Sédhiou ont été constatées par les brigades de Bounkiling ( $38 \%$ ) de Sedhiou $(28 \%)$ et de Samine-Escale $(22 \%)^{39}$. A priori, les zones frontalières semblent donc constituer les principaux pôles de délinquance du département et être « sous-contrôle ».

64 Toutefois, la prise en compte de la nature et de la localisation des infractions constatées par les forces de gendarmerie de Bounkiling ou de Samine Escale puis transmises aux autorités judiciaires, amène à nuancer cette hypothèse. Dans les deux cas, en effet, les infractions liées aux accidents de la route sont nombreuses (environ $40 \%$ du total). Si, à Bounkiling, certains délits ou crimes, tels que la «participation à un mouvement insurrectionnel », les« vols en réunion avec usage d'armes » ou «l'association de malfaiteurs », 
peuvent apparaître comme des manifestations de la rébellion ou du banditisme, par contre, à Samine Escale, certains cas de "culture de stupéfiants", constatés dans des villages situés sur la RN $12^{40}$, donnent à penser qu'il existe un trafic et des réseaux probablement liés à la rébellion. Comme le rappelle d'ailleurs l'Atlas mondial des drogues, «les Ghanéens et Nigérians ont entrepris d'exporter leur modèle de production dans d'autres régions de l'Afrique de l'ouest, en particulier le Sénégal et la Gambie "(Atlas mondial des drogues, 1997 : 111-112). De plus, sous l'impulsion du MFDC, «la taxation sur les cultures illicites par les guérillas existe en Casamance comme dans des régions aussi diverses que les Philippines, l'Indonésie, l'Inde, le Libéria, etc. »(Atlas mondial des drogues, 1997 : 126).

En outre, la plupart des infractions commises dans les villages des communautés rurales $^{41}$ de Diattacounda et de Samine Escale sont dénoncées directement auprès du procureur de Kolda, sous forme de plaintes individuelles, et elles ne sont donc pas constatées par les officiers de police judiciaires qui ont compétence sur ce secteur rural. S'il est normal que les litiges fonciers (« occupation illégale de terrain appartenant à autrui $»^{42}$ ) soient le plus souvent portés à la connaissance de la justice par les villageois eux-mêmes, par contre, les infractions en matière de stupéfiant devraient faire l'objet de surveillance et être constatées par les officiers de police judiciaire à leur propre initiative ou sur dénonciation. Par ailleurs, cette partie de la région relève du tribunal départemental de Sedhiou, géographiquement proche, et non du tribunal régional de Kolda, situé à environ $120 \mathrm{~km}$. Ainsi, bien qu'appauvries par plusieurs années de conflit, les populations préfèrent donc, pour s'assurer du traitement de leur affaire, payer un déplacement relativement coûteux et voyager plusieurs heures sur une route où les attaques de véhicule sont fréquentes. Ce comportement peut traduire une défiance des populations à l'égard des autorités locales chargées de la sécurité dans cette partie de la Casamance. 
Carte 2 : Origine des plaintes ou des procès-verbaux et des affaires enregistrées au tribunal régional de Kolda et provenant du département de Sedhiou - 2002

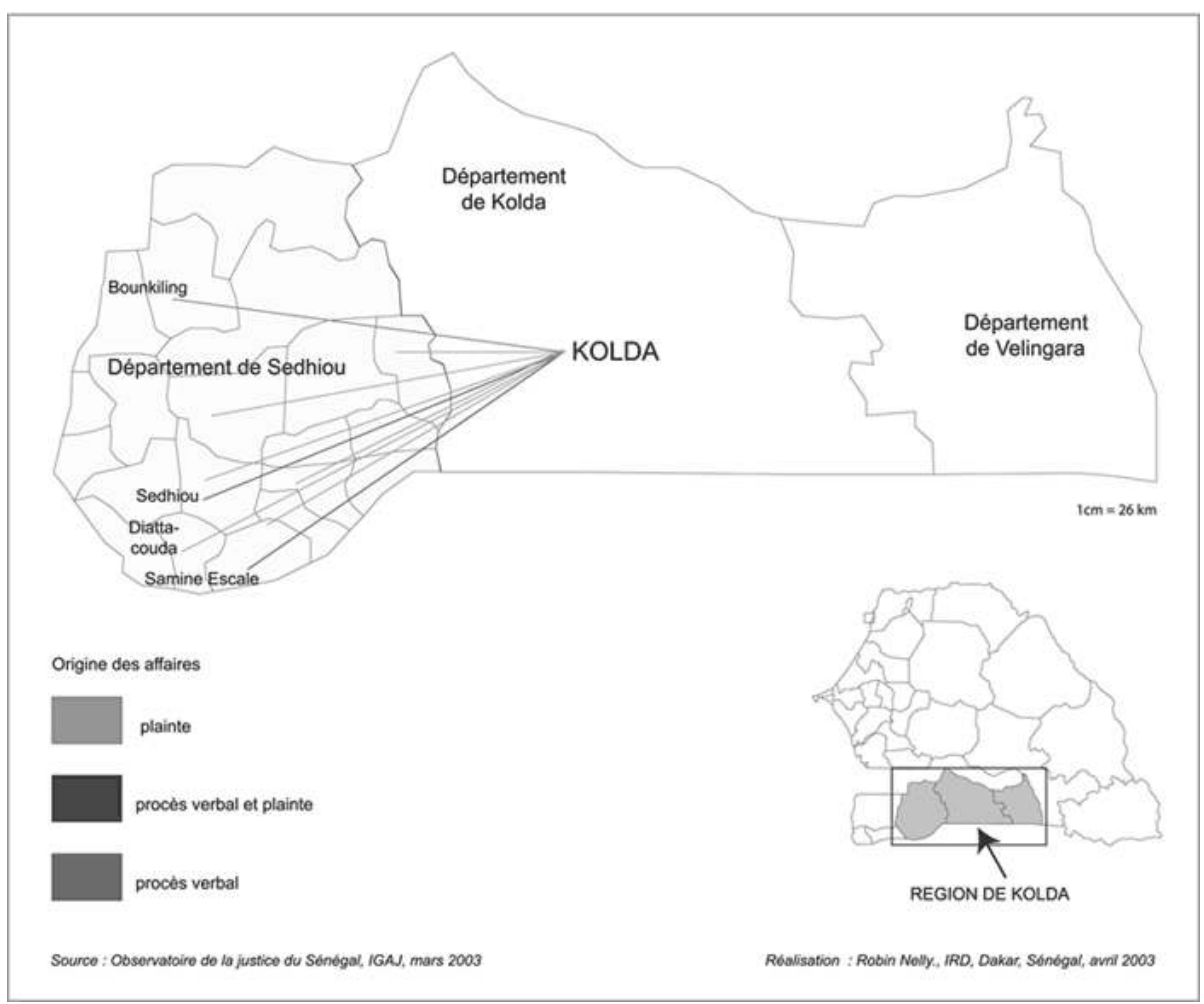

L'analyse des affaires traitées par le parquet régional de Kolda et qui proviennent du sud du département de Sedhiou, révèle donc deux faits importants :

1. les populations font preuve à la fois, de vigilance à l'égard de leurs terres, notamment de leur occupation par un tiers, même si, en raison de l'insécurité, elles ont dû abandonner leur village, et d'une volonté de lutter contre le développement d'activités illicites, spécifiquement la culture de cannabis, qui alimentent et accroissent l'insécurité ;

2. la présence des forces de l'ordre s'estompe en dehors des principaux pôles urbains et des axes routiers. Les populations le constatent ; une partie ne s'y résout pas, mais, au contraire cherche à alerter les autorités judiciaires régionales sur leur situation d'insécurité endémique.

Il y a là comme un appel au secours des villageois, adressé à un État qui semble faire la sourde oreille ou être impuissant à y répondre. En réalité, son silence reflète, plus probablement, sa méconnaissance de la situation. Faute de s'interroger sur les modes de représentation de l'État, dans une zone particulièrement sensible, et sur la perception qu'en ont les populations, l'autorité centrale ignore leur attente réelle et ne mesure pas, à sa juste valeur, la menace qui pèse sur l'État de droit dans cette région.

\section{Un appareil judiciaire marginalisé en Casamance : une menace pour l'intégrité de l'État}

Dans ce contexte, une part importante des faits de délinquance échappe à la justice, ce qui limite d'autant les possibilités de lutte contre la criminalité et les chances de rétablir la sécurité. 
69 Pourtant, si l'on considère que «la justice assume une fonction essentielle de régulation et de stabilité sociale, en assurant le respect des lois et règles de l'organisation sociale et politique d'un pays », elle est alors "un pilier essentiel du système national d'intégrité et, à ce titre, détermine le bon fonctionnement des autres composantes de ce système $»^{43}$. Donc substituer à l'autorité judiciaire un traitement essentiellement militaire des actes de rébellion et de banditisme, ainsi que différents indices sur l'implantation et l'action de l'armée ${ }^{44}$, met en danger l'État de droit en Casamance. Dès lors, le citoyen s'interroge sur les moyens dont l'État se dote pour faire respecter ses droits, notamment dans le domaine foncier. Alors, la tentation devient grande d'un compromis avec les rebelles susceptibles de lui donner satisfaction, au moins pour sa sécurité, contre un « impôt » de guerre, et pour l'accès aux terres de culture, contre un partage négocié des récoltes. Dans cette logique, certains citoyens peuvent même considérer que seul un État casamançais pourra leur donner satisfaction! On aurait là un facteur paradoxal de la persistance du mouvement indépendantiste: par le choix de son mode d'intervention, l'État central sénégalais renforce la revendication d'indépendance.

70 Le témoignage d'un agent de liaison entre les combattants indépendantistes, repliés dans le maquis, et les dirigeants du MFDC, en résidence surveillée à Ziguinchor ou exilés à l'étranger, conforte cette idée. Arrêté en 1984 et interrogé par le procureur de la région de Casamance, il découvre l'arrestation et l'emprisonnement d'un fonctionnaire, qu'il sait être à l'origine de ventes illégales de terres, au bénéfice des "gens du nord $»^{45}$ et au détriment de la population casamançaise. Il fait part de son étonnement et raconte comment lui-même a été spolié par ce dernier et comment il a alerté l'état central ; méfiant à l'égard des autorités locales, il a écrit directement à deux reprises au Président de la République du Sénégal pour dénoncer les agissements de ce fonctionnaire. Il n'a reçu aucune réponse. Pour lui, c'est donc la preuve que l'État se désintéresse de la Casamance et laisse les «étrangers $»^{46}$ piller la population autochtone en toute impunité. Cela suffit à justifier son engagement auprès du MFDC pour l'indépendance.

71 Dans ce contexte, la marginalisation de la justice ou même son absence de fait sur une partie du territoire, risque d'encourager le développement de forces centrifuges et de favoriser l'émergence d'un territoire de non-droit, dans la mesure où «le territoire se définit comme la marque essentielle de l'État »(Di Meo, 2001: 263). À terme, cela peut conduire à une sécession d'une partie ou de l'ensemble de la Casamance.

72 Selon J. Rawls, «une conception politique de la justice, valable dans une démocratie constitutionnelle »(1993: 385), implique que la justice défende les valeurs politiques fondamentales, c'est-à-dire les droits et libertés consacrés par la constitution. Comprise ainsi, la justice donne assez de poids à la démocratie pour qu'elle puisse l'emporter sur toutes les autres valeurs qui pourraient entrer en conflit avec elle et assure une base de coopération équitable, sociale et politique, entre les citoyens.

73 À l'inverse, un État qui ne s'appuie plus sur sa justice, a fortiori dans une région fragilisée par un conflit, est un État qui prend le risque de ne plus garantir à chacun les droits et libertés consacrés par la constitution. Son intégrité est alors menacée : il peut perdre le contrôle exclusif sur son territoire et sur la population résidant dans les zones de non-droit. Dès lors, trois attributs fondamentaux de l'État sont remis en cause : l'exercice de sa souveraineté, le contrôle de son territoire et la définition des contours de sa communauté nationale. 
Face à ce constat, les citoyens cherchent des solutions alternatives pour assurer leur protection et celle de leur territoire. Ils peuvent aussi tenter d'engager un processus de développement autonome, qui pallie les carences ou même l'absence de l'État.

\section{Retours d'exode entre résistance et idéologie}

Cette tendance peut être observée dans le sud du département de Sedhiou ${ }^{47}$ et dans le Youtou ${ }^{48}$, notamment. Le parallèle entre ces deux zones est d'autant plus intéressant que leur population ne présente pas les mêmes caractéristiques sociologiques et que leur implication dans le conflit est différente.

Le sud du département de Sedhiou correspond au pays Balant qui forme comme une enclave dans le pays Mandingue. Ces habitants sont essentiellement agriculteurs même si certains s'adonnent aussi à l'élevage; la plupart d'entre eux sont musulmans. Cette partie de la Moyenne Casamance n'a été touchée que récemment ${ }^{49}$ par le conflit; les populations ont été victimes d'accidents par mines posées par les rebelles ou l'armée, de pillages dans les villages ou de braquages de véhicules, commis par les rebelles ou par des «bandes armées ». Peu d'affrontements directs entre l'armée sénégalaise et le MFDC y ont eu lieu.

77 Plus à l'ouest, les îles du Youtou se situent au cœur du Floup, berceau du peuple joola, agriculteur et animiste. Cette partie de la Basse Casamance constitue un lieu symbolique et une place forte de la rébellion, depuis le début du conflit. Des combats très violents y ont opposé l'armée sénégalaise et les rebelles. Les populations du Youtou ont souvent été soupçonnées de soutenir les combattants du MFDC.

Au cours des années 2001 et 2002, des mouvements de retour apparaissent dans ces deux régions de Casamance. Traduisent-ils la recherche d'une issue à la crise, par un retour négocié avec les rebelles ou les bandits pour l'accès à la terre, et la volonté d'initier un développement autonome de leur communauté villageoise, sans attendre la participation de l'État?

79 Comme nous avons pu l'observer, notamment dans les communautés rurales de Diattacounda et de Samine-Escale ${ }^{50}$, en Casamance, l'État privilégie «la violence» à la place de la «contrainte légitime » en laissant s'estomper l'autorité de la justice au profit de l'ordre militaire. Dès lors, malgré leur « volonté majoritaire de sauvegarder les structures de l'État-nation ", les populations se voient obligées de construire leur propre sécurité en négociant directement avec les forces insurrectionnelles ou avec les « bandits ».

Ainsi, l'analyse des mouvements de populations et des processus de production des territoires qui leur sont liés révèle que dans cette partie du Sénégal, certaines populations, appauvries par vingt ans de guerre et déçues par des accords de paix sans lendemain, tentent de s'organiser sans l'État central. 
Carte 3 : Mouvement d'exode et de retour dans le département de Sedhiou en 2001 et 2002

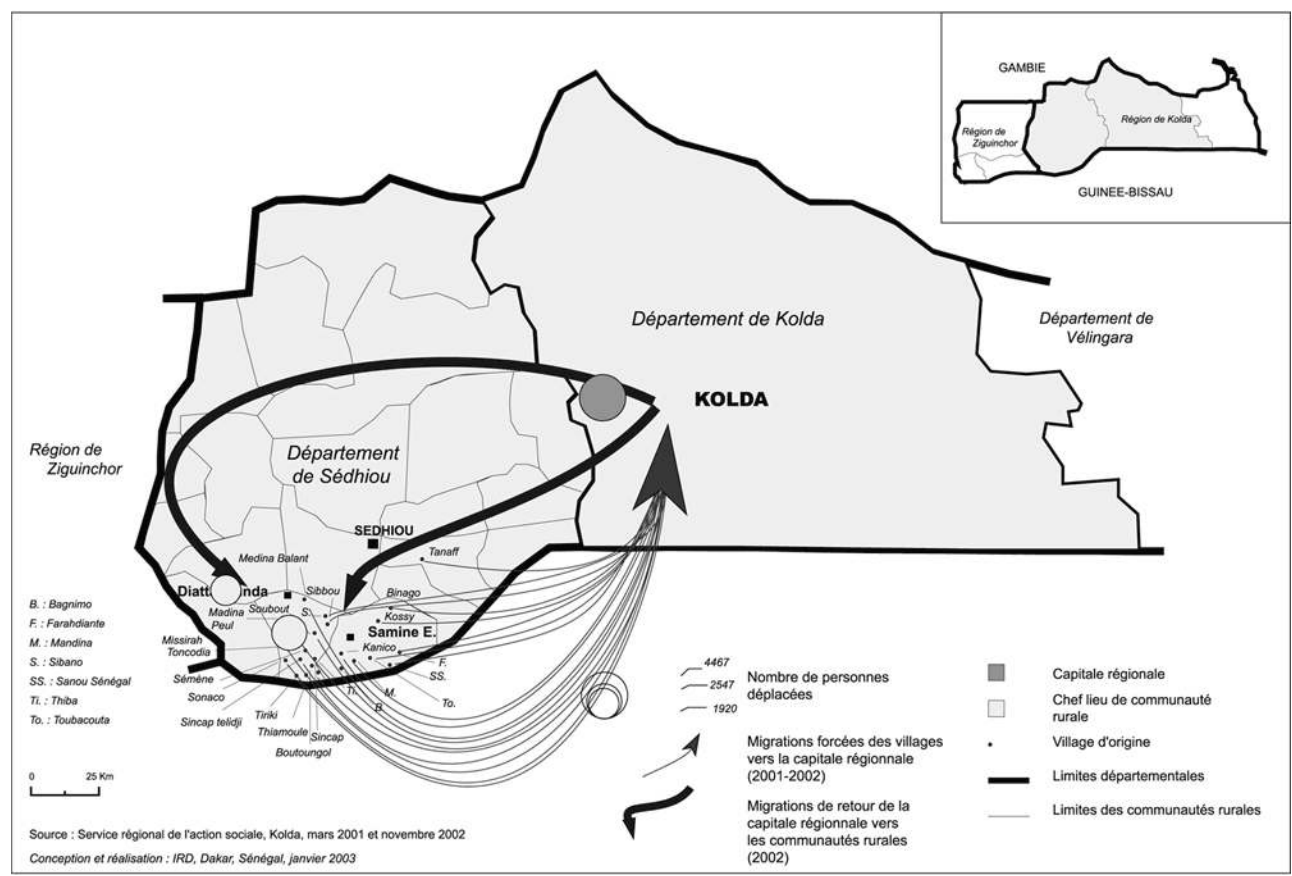

\section{Retours contraints d'une population abandonnée à elle-même ou actes de résistance?}

81 Les mouvements d'exode et de retour, observés au sud du département de Sédhiou, illustrent cette dynamique. En mars 2001, sur environ 20000 personnes déplacées, dénombrées dans la ville de Kolda, $65 \%$ proviennent du département de Sédhiou ; elles sont toutes originaires de villages situés le long de la frontière bissau-guinéenne, dans les communautés rurales de Diattacounda, Samine Escale, Tanaff et Niagha.

Ces populations abandonnées à elles-mêmes à Kolda, et privées de leurs moyens de survie sont contraintes de quitter ce lieu de premier refuge pour se rapprocher de leurs terres agricoles au risque de devoir affronter à nouveau les violences qui, hier, les ont fait fuir. Dans ces conditions, la plupart préfèrent ne pas retourner vivre dans leur village d'origine et s'installent dans les chefs-lieux des communautés rurales, situés le long des axes routiers et considérés de ce fait comme sécurisés. Ainsi, elles peuvent cultiver leurs terres la journée, tout en résidant hors des zones à haut risque.

La carte 3 montre bien ce double mouvement d'exode massif, depuis les villages situés le long de la frontière bissau-guinéenne vers la capitale régionale, Kolda, et de retours "négociés » dans les chefs-lieux des communautés rurales de Samine-Escale et de Diattacounda.

Mais, quelle stratégie ou quel dilemme sous-tend le retour de ces populations dans des territoires exposés aux dangers de la rébellion ou du banditisme? En fait, ces villageois s'engagent dans un processus de retours « obligés » faute d'autres solutions possibles; mais on pourrait aussi parler de retours « résistants » pour ceux qui sont animés par la volonté de préserver leurs terres, menacées de déshérence ou de confiscation de fait. Toutefois, face aux déficiences des institutions régionales et à la gestion exclusivement sécuritaire d'un conflit confié à l'armée, ces populations se voient obligées de négocier 
avec les bandes armées pour une réinstallation précaire dans leur territoire : la sécurité dans les villages et l'accès aux zones de culture sont acquis au prix du racket ou de l'impôt de guerre prélevés par des rebelles, qu'ils le soient effectivement ou qu'ils soient présumés tels.

\section{Initiatives de développement ou stratégie d'autonomie?}

de sortie de crise et une volonté de développement. Ce nouveau discours qui concilie la sensibilité des populations réfugiées de retour et des populations restées dans le maquis, comme celle des organisations internationales susceptibles de soutenir des projets de développement, semble faire fi du passé de revendication indépendantiste, sans le trahir. Ces populations qui avaient fui dans un climat de terreur et ont vécu plusieurs années dans une grande précarité, souvent dans la clandestinité car elles étaient soupçonnées de soutenir les rebelles, reviennent, à leur propre initiative, reconstruire leur village et remettre en culture leurs terres. Pour réaliser ce projet elles ne demandent rien à l'État du Sénégal et n'attendent rien de lui. Ainsi, elles adoptent une démarche conforme à leur revendication initiale : l'autodétermination pour l'usage de leurs terres ancestrales.

Mais ces initiatives risquent aussi de porter en filigrane les germes de nouveaux pouvoirs. Cette hypothèse semble confortée par l'intérêt porté aux jeunes du Youtou, à l'origine des mouvements de retour, par les organisations des droits de l'homme qui entendent être leaders du processus de paix ou par les élus locaux de la région, intéressés et inquiets à la fois.

89 Ainsi, les migrations de retour et les nouveaux rapports au territoire dans lequel elles s'inscrivent, au sein de deux régions de Casamance très différentes par leur réalité sociologique et leur participation au conflit, permettent de «déceler des polarisations conflictuelles tendant à effriter l'unité nationale »(Di Meo, 2001 : 272). À terme, le territoire local peut devenir la référence principale de l'identité des populations; il fonde et légitime leur combat, qu'il soit mené volontairement ou qu'il procède de l'obligation de survie.

\section{Conclusion}

90 Ces retours, dont les populations prennent l'initiative, révèlent que l'État se dérobe devant une gestion politique des causes des migrations forcées en Casamance et qu'il esquive un traitement social de leurs conséquences.

Revue européenne des migrations internationales, vol. 22 - $n^{\circ} 1$ | 2006 
91 Ainsi, les carences de l'État en matière de sécurité et d'assistance aux populations, dans un territoire sécessionniste et marqué par un banditisme dont l'origine est encore imprécise ${ }^{51}$, posent la question de l'État de droit et de l'intégrité territoriale.

Les reports successifs des négociations qui devaient suivre l'accord de paix signé le 30 décembre 2004, soulignent les difficultés rencontrées par le MFDC pour harmoniser le point de vue des différentes factions qui le composent ${ }^{52}$, préliminaire indispensable à l'instauration d'une paix durable reconnue par tous. Cela quelle que soit l'authenticité des initiatives de négociation ou de développement portées par les groupements de villageois, " pris au piège » d'une guerre qui manifestement les dépasse et ressemble de plus en plus à "ces conflits de "basse intensité" qui constituent des pions dans des jeux d'influences complexes $»^{53}$. Les populations qu'elles soient restées dans leur village ou qu'elles se soient déplacées vers des zones sécurisées, notamment Ziguinchor, partagent aujourd'hui la même aspiration: la paix et la possibilité d'exploiter à nouveau leurs terres. Malgré ce consensus, les attaques dans les villages ou sur les routes et les accrochages entre l'armée sénégalaise et des bandes armées se poursuivent. De plus, chaque tentative de négociation entre l'abbé Diamacoune, secrétaire général du MFDC, et le gouvernement du Sénégal, engendre un regain de violence, comme s'il s'agissait de "préserver » l'insécurité en Casamance. Cela pose la question de la représentativité des leaders actuels du MFDC, tant vis-à-vis de la population que vis-à-vis des rebelles eux-mêmes. Ainsi, comme pour d'autres guérillas en Afrique, on est en droit de s'interroger sur les enjeux sous-régionaux ou internationaux qui seraient susceptibles d'inciter certains acteurs, politiques ou économiques, sénégalais ou étrangers, à maintenir volontairement la Casamance dans l'insécurité...

93 Bien qu'elles n'aient pas les mêmes causes ni la même histoire, il est difficile de ne pas s'interroger sur les liens éventuels entre la guerre de Casamance et la série de conflits qui affectent le Libéria, la Sierra Leone et la Guinée-Conakry, depuis de longues années, et ont récemment gagné la Côte d'Ivoire. La guerre de Casamance s'inscrit-elle dans un " système de conflits ", " produits de conjonctures nationales distinctes, relevant d'acteurs, de modalités et d'enjeux différents (qui) s'articulent les uns aux autres et brouillent les frontières spatiales, sociales et politiques qui les distinguaient initialement»?Si tel était le cas, la rébellion et le banditisme qui sévissent en Casamance ne constitueraient plus seulement un risque pour l'intégrité nationale du Sénégal mais devraient être perçus comme un danger supplémentaire pour la stabilité de l'Afrique de l'ouest.

Cette menace de déstabilisation sous-régionale pourrait être liée, en partie, aux "économies trafiquantes", c'est-à-dire à " une juxtaposition de réseaux aux activités licites et illicites et, par conséquent, une articulation entre formel et informel qui rend obsolète les problématiques classiques de l'État en Afrique "(Botte, 2002 : 131-152). Le lien entre les guerres civiles du Liberia et de la Sierra Leone et le trafic illicite de diamants n'est plus à établir. Dans le contexte casamançais, le trafic illicite de stupéfiants serait-il un des «non-dits » du conflit qui pérennise l'insécurité et hypothèque les initiatives de paix ? L'Atlas mondial des drogues (1997: 111) précise que la «taxation sur les cultures illicites par les guérillas existe dans des régions du monde aussi diverses que les Philippines ${ }^{54}$, l'Indonésie ${ }^{55}$, l'Inde ${ }^{56}$, le Sénégal (Mouvement des forces démocratiques de Casamance), le Liberia ${ }^{57}$, etc. " Source de financement de la guerre de Casamance, la culture de cannabis n'en seraitelle pas devenue l'un des enjeux, avec le commerce de la noix de cajou et du bois de veine, notamment? La crise politique et économique qui affecte la Casamance a une 
incidence incontestable sur la production de cannabis et le trafic de marijuana dans le reste du pays. Des sources proches de la police de Kolda (Haute Casamance) ont déclaré au correspondant de la Lettre Internationale des Drogues ${ }^{58}$ que « plus de la moitié de la marijauna saisie sur le marché de Diaobé $e^{59}$, quand elle ne vient pas de la République de Gambie, arrive des zones forestières, refuge de la rébellion casamançaise. "En outre, dans un article récent, Fanchetteprécise qu'à« Diaobé on a mis aussi au jour un plantureux trafic d'armes en provenance du Liberia et de la Sierra Leone, susceptible soit d'alimenter la rébellion casamançaise, soit de fomenter la chute du régime du président Yaya Jammeh "(Fanchette, 2001 : 91-115). Selon le même auteur, le«trafic d'armes serait si étendu que les autorités nationales (sénégalaises) craindraient pour la sécurité de la région».

En fait, la position géographique de la Casamance est favorable au développement de réseaux d'exportation de marijuana, destinée aux marchés de consommation, européens notamment; les îles Karonnes, principale zone de culture de cannabis en Casamance, sont bordées à l'ouest par l'océan Atlantique et au nord par un fleuve, frontière naturelle entre le Sénégal et la Gambie, elle-même reconnue comme une plate-forme de la contrebande régionale et un pôle actif de transit des drogues ${ }^{60}$.

Cette réalité proche du monde du crime et des mafias, mais souvent éludée par les autorités sénégalaises comme par les rebelles, rend parfois délicate l'analyse scientifique du conflit casamançais dont l'un des enjeux sous-jacents est aussi l'image internationale du Sénégal, reconnu comme la vitrine démocratique de l'Afrique de l'ouest et dont la stabilité politique constitue aujourd'hui, plus que jamais, un enjeu majeur pour la sous-région.

\section{BIBLIOGRAPHIE}

Atlas mondial des drogues (1997) Observatoire géopolitique des drogues, Paris, PUF, pp. 111-112 et p. 126.

BOTTE Roger (2002) Économies trafiquantes et mondialisation : la voie africaine vers le développement? Politique Africaine, 88, pp. 131-152.

DI MEO Guy (2001) Géographie sociale et territoires, Paris, Nathan université.

FANCHETTE Sylvie (2001) Désengagement de l'État et recomposition d'un espace d'échange transfrontalier : la Haute-Casamance et ses voisins, Autrepart, 19, pp. 91-115.

GEFFRAY Claude (1998) Cocaïne, richesses volées et marché légal, Autrepart, 8, p. 174.

MARCHAL Roland (2002) Liberia, Sierra Leone et Guinée : une guerre sans frontières ? Politique Africaine, 88, pp. 5-12.

NDIAYE Mandiogou et ROBIN Nelly (2001) Personnes déplacées ou réfugiées de la région de Ziguinchor. Une dynamique de conflit empreinte d'histoire,IRD-OIM, Dakar.

PEROUSE DE MONTCLOS Marc Antoine (1998) Le poids de l'histoire et le choc des cultures : les réfugiés somaliens du Kenya confrontés à la raison d'État, Autrepart, 7, pp. 155-172. 
RAWLS John (1993) Justice et démocratie, Paris,Seuil, Points, 385 p.

RECLUS Elysée (1998) L'homme et la terre, Paris, La Découverte/Poche Sciences humaines et sociales, $398 \mathrm{p}$.

ROCHE Christian (1985) Histoire de la Casamance. Conquête et résistance : 1850-1920, Paris, Karthala, 288 p.

\section{NOTES}

1. Source : le rapport annuel 2004 du Haut Commissariat des Nations Unies pour les réfugiés.

2. En 1983, la région de Casamance est subdivisée en deux régions administratives : la région de Ziguinchor et la région de Kolda.

3. Selon l'observatoire géopolitique des drogues, en Casamance, le paysan reçoit 300000 francs CFA pour une superficie de $10 \mathrm{~m}^{2}$ de cannabis ; sur la même superficie, le mil, culture vivrière traditionnelle, lui rapporte seulement quelques centaines de francs CFA?

4. Combattre la corruption: enjeux et perspectives. Chapitre 9, "L'indépendance du système judiciaire », p. 154.

5. Article 8 de la Déclaration universelle des droits de l'homme.

6. Déclaration de l'abbé Diamacoune, Ziguinchor, 8 mars 2001.

7. Office de la Radiodiffusion et de la Télévision Nationale.

8. Personnes originaires d'autres régions du Sénégal.

9. Il accrédite sa thèse en faisant référence à un texte qui selon lui tend à prouver que la Casamance aurait été confiée en 1960 au Sénégal.

10. Le MFDC originel avait fusionné avec le parti de Léopold Sedar Senghor.

11. Jusqu'en 1983, la région administrative de Casamance réunissait les deux régions administratives actuelles de Ziguinchor et de Kolda.

12. Au Sénégal, la gouvernance est l'édifice où réside le gouverneur, responsable de l'ensemble des services administratifs d'une région.

13. À la suite de la manifestation indépendantiste de 1983, Sidy Badji se retranche dans le maquis et crée, à Mandina (au sud de Ziguinchor), « Atika », l'aile militaire du MFDC.

14. L'aile radicale du mouvement est alors animée par trois chefs rebelles: Léopold Sagna, Mathieu «Gagarine » et Salif Sadio. Après le cessez-le-feu de 1993, de jeunes maquisards du "Front sud", peu enclin à déposer les armes, se regroupent derrière cette nouvelle génération de chefs rebelles. En 1994, Léopold Sagna, successeur de Sidi Badji, sera évincé à la suite de sa rencontre secrète avec le Président de la République du Sénégal, Abou Diouf. Par la suite, Salif Sadio s'imposera comme le seul chef du « Front sud ». En 2001, après un regain de tensions, l'État du Sénégal lance un mandat d'arrêt contre lui. Au cours de l'année 2002, il est déclaré mort à la suite d'affrontements avec l'armée sénégalaise. Cependant, plusieurs témoignages semblent indiquer qu'il est toujours vivant. Dans un communiqué du 19 mai 2003 qui émanerait de sa main, il dénonce la rencontre entre le chef de l'État du Sénégal, $\mathrm{M}^{\mathrm{e}}$ Wade, et l'abbé Diamacoune, le 4 mai 2003, et clame "le droit de la Casamance à l'indépendance. »

15. Chiffres confirmés par les données de l'Hôpital régional de Ziguinchor et par la Légion de gendarmerie de la zone sud, basée à Ziguinchor.

16. Le 7 juin 1998, débute un soulèvement militaire par une attaque de l'état-major de l'armée de terre à Bissau. L'insurrection a pour origine le limogeage du chef d'état-major des Forces armées, le général Ansumane Mané, dans le cadre d'une affaire de trafic d'armes vers la Casamance. Le président Joao Bernado Vieira est renversé en 1999. Un nouveau chef d'État, Kumba Yala, est élu en janvier 2000. Ansumane Mané meurt peu après. Le nouvel homme fort de Guinée-Bissau 
affiche d'emblée sa volonté de détruire les bases arrières du MFDC, installées sur son territoire, le long de la frontière avec le Sénégal.

17. Lettre du 3 janvier 2001, signé par Salif Sadio, Chef d'état-major général du maquis.

18. 303 réfugiés de retour de Guinée-Bissau ont été accueillis entre le 28 mai et le 31 juillet 2001 à Ziguinchor par la "Cellule de coordination pour la gestion des réfugiés rapatriés et personnes déplacées " puis orientés vers les villages ou les villes de résidence de leur famille. Ces informations sont répertoriées dans le rapport d'activité du Chef de service du développement communautaire de Ziguinchor (23 août 2001).

19. Deux exemples peuvent illustrer notre propos. Ainsi, le département de Bignona, situé au nord, entre le fleuve Casamance et la frontière gambienne, et l'arrondissement de Diattacounda, situé au sud du département de Sedhiou, le long de la frontière bissau-guinéenne, ont été relativement peu touchés par les déplacements de population jusqu'en 2000. Lorsque le processus de paix est relancé, après l'élection de Wade, les attaques, attribuées aux rebelles du MFDC ou à des bandes armées non contrôlées se multiplient dans ces deux parties de la Casamance et entraînent le déplacement de plusieurs milliers de personnes. Selon l'observatoire géopolitique des drogues, «les îles du delta du Saloum et des fleuves Gambie et Casamance sont les principales zones de production (de cannabis) dans la région ». Les opérations menées par la gendarmerie nationale, entre 1995 et 1999, dans le cadre de la lutte contre le trafic illicite de stupéfiants confirment ces informations : dans les îles Karones, à Saloulou et à Hilol, 259, 5 hectares de champs de cannabis, au moins, ont été détruits (source : Gendarmerie territoriale, 21 mai 2001). Ces zones de cultures sont situées dans l'ouest du département de Bignona. À l'inverse, les terres de culture de l'arrondissement de Diattacounda sont essentiellement vouées à la riziculture et à l'arboriculture.Ces deux zones de Casamance sont donc confrontées, au même instant, à un même contexte (attaques et déplacements de populations) mais présentent deux environnements différents (culture de cannabis ou cultures vivrières) qui induisent inévitablement des enjeux différents.

20. Juin-juillet 2001.

21. Juin-juillet 2002.

22. Sources: Gouvernance de Ziguinchor (14/09/2002) et Association des frères unis pour le développement économique et social du Fogny (AFUDES), juillet 2002.

23. Sources : Croix Rouge de Gambie et HCR, juillet 2002.

24. Sources : Service régional de l'action sociale, Kolda. Mars 2001 et janvier 2003.

25. Les autres ont préféré se rapprocher de leur village d'origine dans l'espoir de pouvoir à nouveau accéder à leurs terres de culture.

26. Village situé dans l'arrondissement de Sindian, département de Bignona.

27. La région du Foñi correspond aujourd'hui aux arrondissements de Sindian, de Tendouk et de Tenghory qui composent, le département de Bignona, avec l'arrondissement de Diouloulou incluant les régions du Kombo et des îles Karones.

28. Archives du Sénégal, 13G383. Lettre du gouverneur général Clozel au gouverneur Cor, 8 avril 1916. Cité par Christian Roche (1985 : 339-340).

29. 7 juin 2001.

30. Chef des Seliki, groupe rebelle situé en Basse Casamance, à la fin du XIx $x^{e}$ siècle.

31. Selon un membre du Collectif des cadres casamançais, « les manifestations les plus marquantes de ce frémissement social étaient perceptibles (...) surtout à travers les remous provoqués par des opérations de lotissement très mal gérées à Ziguinchor et des spoliations -de terre ici et là en Casamance ». Y.Mane, Éléments de réflexion sur la crise casamançaise. Forum du Collectif des cadres casamançais, novembre 2000, Ziguinchor, 11 p. Dans un fascicule publié sous le titre "La vérité sur la Casamance ", l'État du Sénégal indique que "l'appropriation par des autorités locales des terres dans la région" et «l'imposition des lois, singulièrement sur le domaine national et le code forestier, ne tenant pas compte des 
us et coutumes des populations de la région" sont des "raisons évoquées par le MFDC pour justifier sa démarche».

32. Un accord destiné à ramener la paix en Casamance a été signé le 30 décembre 2004 à Ziguinchor par le ministre sénégalais de l'intérieur et par le chef du Mouvement des Forces Démocratiques de Casamance (MFDC). Cet accord constituait le prélude aux négociations ouvertes le $1^{\text {er }}$ février 2005 à Foundiougne, dans la région de Fatick, entre les deux parties ; elles devaient s'achever fin mai 2005, selon un communiqué conjoint, et prévoyaient des réunions tous les quinze jours. En fait, le démarrage de Foundiougne II, qui marque la deuxième phase des négociations, a été reporté à deux reprises puis de nouveau renvoyé sine die le 24 mars 2005.

33. Personnes originaires d'autres régions du Sénégal.

34. Toutefois, chacun semble reconnaître que depuis le dernier changement de commandement, le comportement de l'armée à l'égard des populations civiles s'est amélioré en Casamance.

35. Région de Kolda, l'une des deux régions administratives de la Casamance.

36. Observatoire de la justice du Sénégal, années 1998 et 2002. Inspection Générale de l'Administration de la Justice du Sénégal, mars 2003.

37. Le département de Sédhiou, situé dans la région de Kolda, est l'une des zones touchées par les déplacements récents de population, voir partie II.

38. $1998: 1251$ affaires, $2001: 1006$ affaires.

39. Source : Observatoire de la Justice du Sénégal, mars 2003.

40. Villages de Temento et Simbandi Balant, notamment.

41. Les communautés rurales ou les communautés urbaines constituent les plus petites unités du découpage administratif du Sénégal; l'arrondissement constitue le niveau supérieur, puis le département et enfin la région.

42. Selon les statistiques pénales, les victimes des «occupations illégales de terrain appartenant à autrui» sont des cultivateurs de Samine-Escale et les personnes mises en cause sont des cultivateurs de Tanaff, la communauté rurale voisine.

43. Combattre la corruption: enjeux et perspectives. Chapitre 9, "L'indépendance du système judiciaire », p. 154.

44. La répartition des accidents par mines dont les victimes sont des militaires constitue, notamment, un indicateur précieux sur les zones d'action de l'armée.

45. On nomme ainsi les personnes affectées en Casamance comme fonctionnaire ou celles venues s'installer comme commerçant.

46. Personnes originaires des autres régions du Sénégal.

47. Sud-ouest de la région de Kolda.

48. Au sud-ouest de la région de Ziguinchor, non loin de l'océan Atlantique.

49. Deuxième partie de la décennie 1990 .

50. Au sud du département de Sédhiou, voir partie III, "Une délinquance constatée par les forces de l'ordre le long des axes routiers, dénoncée par les populations elles-mêmes en milieu rural ».

51. Plusieurs hypothèses sont avancées : les uns pensent que ce sont des bandes armées n'ayant aucun lien avec le MFDC et réunissant des hommes d'origine étrangères, des Sierra léonais ou des Libériens notamment, qui opèrent sur le territoire sénégalais à partir de la Gambie et de la Guinée-Bissau, où ils auraient installé leurs bases arrières. D'autres privilégient la thèse des "villageois complices» des bandes armées. Ainsi, à la suite d'un accrochage dans le village de Belaye (département de Bignona), le 18 mai 2003, entre l'armée sénégalaise et une bande armée, un communiqué du commandant de cette zone militaire (Comzone, $n^{\circ} 5$ ) précisait que ces bandes étaient composées d'originaires des villages situés le long de l'axe Koronko-Nemo-DjimakiBadiana-Belaye. D'ailleurs, selon le commandant de zone, le villageois accusé de connivence avec les assaillants aurait confirmé " avoir hébergé dans son domicile de Belaye des rebelles dans la nuit du vendredi au samedi » (Walfadjiri, 20 mai 2003, « Insécurité en Casamance », p. 6). 
52. Depuis le report sine die des négociations le 24 mars 2005, les dissensions entre les différentes factions du MFDC apparaissent de plus en plus au grand jour et les attaques à main armée sur les routes de Casamance ou dans les villages, qui avaient connu une réelle accalmie, deviennent plus fréquentes et génèrent de nouveaux déplacements de population.

53. "Géopolitique du chaos unipolaire ", Atlas du Monde diplomatique. Hors série de «Manière de voir », janvier 2003, p. 86.

54. Front national de libération de Mindanao.

55. Front de libération d'Aceh Sumatra.

56. Conseil national socialiste de Nagaland.

57. Front national patriotique du Liberia.

58. Lettre Internationale des Drogues (LID), "Sénégal. Le gouvernement change, le trafic continue», janvier 2002.

59. Village situé au sud du département de Vélingara, région de Kolda.

60. Par ailleurs, comment lutter contre le développement d'une culture dont le kg est payé bordchamp jusqu'à 61 euros (selon la LID) au paysan casamançais, alors que dans le même temps, le prix de l'arachide, principale culture de rente du Sénégal, s'effondre et plafonne à 0,09 euros le kg (120 CFA).

\section{RÉSUMÉS}

Cet article est centré sur l'analyse des déplacements de population liés à l'un des conflits les plus longs de l'Afrique sub-saharienne qui oppose, au sud du Sénégal, le gouvernement aux séparatistes du Mouvement des Forces Démocratiques de Casamance (MFDC). Il s'agit de comprendre les processus qui ont généré les migrations de réfugiés ou de personnes déplacées, appréhender leur évolution et apprécier leurs implications sociales et politiques sur la situation actuelle de la Casamance. Un parallèle est ensuite établi entre les rapports que les populations de Casamance ont entretenus avec l'administration coloniale et les relations qu'elles ont avec les représentants de l'État du Sénégal depuis le début du conflit. Cette mise en perspective de deux temps de l'histoire permet de mieux comprendre les fondements de la défiance des populations à l'égard des autorités administratives ou militaires et l'importance de la question foncière pour la construction de la paix.

This article is centred on the analysis of displacements of population related to one of the longest conflicts of sub-Saharan Africa which opposes, in the south of Senegal, the government with the separatists of the Movement of the Democratic Forces of Casamance (MFDC). It is a question of understanding the processes which generated the migrations of refugees or displaced people, to apprehend their evolution and to appreciate their social and political implications on the current situation of Casamance. A parallel is then established between the relations that the populations of Casamance maintained with the colonial administration and the relations that they have with the representatives of the State of Senegal since the beginning of the conflict. This setting in two times prospect of the history makes it possible to better understand the bases of the distrust of the populations with regard to the administrative or military authorities and the importance of the land question for the construction of peace. 
Este artículo se centra en el análisis de los desplazamientos de población ligados a uno de los conflictos más largos del África sub-sahariana que opone, en el sur de Senegal, al gobierno y a los separatistas del Movimiento de Fuerzas Democráticas de Casamance (MFDC). Se trata de comprender los procesos que han generado las migraciones de refugiados o de personas desplazadas, de entender su evolución y de apreciar sus implicaciones sociales y políticas sobre la situación actual de Casamance. Un paralelo es a continuación establecido entre las relaciones que las poblaciones de Casamance crearon con la administración colonial y las relaciones que estas mismas poblaciones han establecido con los representantes de Estado de Senegal desde el inicio del conflicto. Este análisis comparado de dos momentos de la historia permite comprender mejor los fundamentos de la desconfianza de las poblaciones respecto a las autoridades administrativas o militares y la importancia de la cuestión de la tierra para la construcción de la paz.

INDEX

Mots-clés : conditions de vie, exode, habitat, population déplacée, retour

Index géographique : Sénégal

\section{AUTEUR}

\section{NELLY ROBIN}

Géographe, Chargée de recherche à l'IRD BP 1386, Dakar, Sénégal. 